\title{
ANÁLISE DA FRAGMENTAÇÃO DO DIREITO INTERNACIONAL À LUZ DO CONSTITUCIONALISMO GLOBAL ORGÂNICO
}

\section{ANALYSIS OF FRAGMENTATION OF INTERNATIONAL LAW IN THE LIGHT OF THE GLOBAL ORGANIC CONSTITUTIONALISM}

\author{
${ }^{1}$ Iana Melo Solano Dantas \\ ${ }^{2}$ Vaninne Arnaud de Medeiros Moreira
}

\section{RESUMO}

Internacional, que se acentua na medida em que os processos de globalização e desenvolvimento econômico se expandem. O objetivo principal foi o de analisar o constitucionalismo global orgânico como solução aos problemas que o Direito Internacional enfrenta em decorrência da fragmentação do mesmo. A proposta metodológica é conceitualteórica. Utiliza-se o método dedutivo e a técnica de pesquisa é documental. Ao final, constouse a possibilidade de utilização da teoria de Schwöbel, no sentido de reconfiguração do Direito Internacional para um Constitucionalismo Global Orgânico.O presente trabalho se justifica diante do fenômeno da fragmentação do Direito

Palavras-chave: Direito internacional, Fragmentação, Constitucionalismo global

\begin{abstract}
The present work is justified by the fragmentation of the phenomenon of international law, which increases the extent that the processes of globalization and economic development expand. The main objective was to analyze the organic global constitutionalism as a solution to the problems that international law faces due to the fragmentation of it. The methodology is conceptual-theoretical. It uses the deductive method and the research technique is documentary. Finally, it comprised the possibility of using Schwöbel theory, towards reconfiguring the international law for a Global Organic Constitutionalism.
\end{abstract}

Keywords: International law, Fragmentation, Global constitutionalism

\footnotetext{
${ }^{1}$ Mestra e em Direito pela Universidade Federal da Paraíba - UFPB, Paraíba, PB. (Brasil). Professora Universidade Federal da Paraíba - UFPB, Paraíba, PB. (Brasil) E-mail: ianasolano@ yahoo.com.br.

${ }^{2}$ Doutora em Ciências Jurídico-Sociais pela Universidad del Museo Social Argentino, UMSA, (Argentina). Professora na Universidade Federal de Campina Grande, Centro de Ciências Jurídicas e Sociais - UFCG, Paraíba, PB. (Brasil). E-mail: vaninne.arnaud@ufcg.edu.br.
} 


\section{INTRODUÇÃO}

A ordem jurídica internacional, em uma concepção clássica, era concebida como uma ordem dotada de coerência e organização funcional. Sua unidade não chegava a ser contestada, configurando-se como um todo rígido, resistente aos avanços dos tempos. A harmonização das interações entre os Estados consistia no objetivo primeiro do Direito Internacional.

Com o fenômeno da globalização e com o desenvolvimento das relações internacionais, tais características passam a perder seu caráter absoluto. Deste modo, é de se constatar que a dinamicidade do cenário internacional traz novos desafios ao Direito Internacional. A tarefa de tutela de relações jurídicas de elevada complexidade técnica e em constantes transformações passa, de forma progressiva, a ser desempenhada por instâncias próprias especializadas, com racionalidades específicas. O legislador nacional não se revela eficiente em todas as matérias que se propõe a normatizar, cedendo espaço para novos sujeitos de direito - o exemplo mais notável são as organizações internacionais. O Direito Internacional perde cada vez mais sua unidade, passando a se configurar de modo fragmentado.

Nesse ínterim, observa-se que a constitucionalização do Direito Internacional também nasce como uma resposta à globalização, e a ideia de constitucionalismo global surge como uma tentativa de solucionar os problemas enfrentados pelo Direito Internacional contemporâneo, tais como a fragmentação do mesmo em diversos regimes ou microsistemas supostamente autosuficientes, tais como, a Organização Mundial do Comércio- OMC, o direito ambiental, os direitos humanos, entre outros.

Diante da realidade fática da fragmentação por que passa o Direito Internacional, uma das soluções apresentadas é a utilização da ideia formulada por Schwöbel (2010), referente ao Constitucionalismo Global Orgânico.

Destarte, o presente trabalho, objetiva, por conseguinte, analisar se o constitucionalismo global orgânico poderia ser uma solução aos problemas que o Direito Internacional enfrenta em decorrência da fragmentação do mesmo.

Para tanto, tentar-se-á responder à problemática formulando a hipótese de que o Constitucionalismo Global Orgânico apresenta-se como um instrumento salutar para solucionar a questão da fragmentação do Direito Internacional, na medida em que o 
Constitucionalismo Global Orgânico rejeita a ideia de universalidade, unidade e homogeneidade, o que acaba indo ao encontro da situação fático-jurídica que se encontra instaurada, quanto à presença cada vez maior de microcosmos jurídicos dentro do Direito Internacional geral. Conforme será explanado, o Constitucionalismo Global Orgânico rejeita a estabilidade em favor da flexibilidade e essa fluidez seria capaz de agregar os mais diversos microsistemas que surgem oriundos da fragmentação do Direito Internacional, através da comunicação, participação e inclusão, que são temas chaves do Constitucionalismo Global Orgânico.

A proposta metodológica é conceitual-teórica. Utiliza-se o método dedutivo, partindo da pressuposição mais ampla da relação entre constitucionalismo global e o subsequente constitucionalismo global orgânico. A técnica de pesquisa é documental, eminentemente bibliográfica.

Deste modo, para alcançar os objetivos dessa pesquisa, sugere-se, inicialmente, que a quebra da unidade do Direito Internacional não deve ser vista como um fenômeno de todo negativo, mas como uma oportunidade de busca de novos elementos capazes de promover a interação entre as instâncias fragmentadas do Direito Internacional. Em um primeiro momento serão apresentados os principais elementos caracterizadores da fragmentação do Direito Internacional. Dar-se-á atenção à atual dinâmica de funcionamento da ordem jurídica internacional, por sua vez resultado de um longo processo histórico.

Posteriormente, será feita uma abordagem inicial sobre em que contexto o Constitucionalismo Global Orgânico está inserido, para tanto, analisar-se-á a constitucionalização do Direito Internacional e o Constitucionalismo Global, para só então apresentar a teoria perfilhada por Schwöbel (2010) e averiguar, por fim a viabilidade da mesma como instrumento capaz de solucionar o processo de fragmentação por que passa o Direito Internacional.

\section{DIREITO INTERNACIONAL: ENTRE A FRAGMENTAÇÃO E A UNIDADE}

A caracterização da ordem jurídica internacional é tarefa das mais árduas. O Direito Internacional passou - e, de forma sistemática, ainda vem passando - por transformações das mais diversas, tendo sua gênese enraizada com respeito à concepção westphaliana do moderno Estado-nação do século XVII, passando por severas críticas quanto ao seu papel de instância última na manutenção da paz mundial e de promotor do desenvolvimento dos povos. 
O debate acerca da natureza jurídica do Direito Internacional seria, de acordo com Hart (1961), infundado, porquanto em sua concepção o Direito Internacional consistiria em um sistema jurídico primitivo. Neste sistema primitivo estariam presentes apenas as denominadas normas primárias, ao passo que o elemento caracterizador dos sistemas jurídicos modernos, as denominadas normas secundárias, restaria ausente da ordem jurídica internacional. O Direito Internacional representaria, em outros termos, um conjunto desordenado de normas jurídicas primárias, e aguardaria sua evolução para um sistema jurídico de maior complexão - o que se caracterizaria a partir da existência de normas secundárias que conferissem validade às normas internacionais.

Pois bem, encontra-se no pensamento de Kelsen (1998) argumentos um tanto quanto diferentes dos de Hart (1961). A separação completa entre Direito e Moral é observada também em nível internacional, de modo que o Direito Internacional se encontraria em estágio de evolução. É forçoso, nesta seara, reconhecer que Kelsen desenvolve seus estudos da ordem jurídica internacional adotando como ponto de partida - e talvez, inclusive, como ponto de chegada - a analogia com a ordem jurídica dos Estados- nação. O Direito Internacional, portanto, seria construido seguindo estritamente os mesmos moldes das ordens jurídicas modernas.

Outro ponto a ser identificado em Kelsen é a vinculação entre Direito e sanção. A ordem jurídica, conforme propõe a clássica obra Teoria Pura do Direito, conta como característica fundamental o fato de ser uma ordem coercitiva. Nesse sentido, se há coação, há Direito; o Direito Internacional seria, seguindo este entendimento, uma ordem jurídica dotada de coação e que se encontra em estágio de evolução inicial, uma vez que se encontram presentes os elementos normativos mínimos e essenciais.

Cumpre observar que os referidos entendimentos acerca da natureza jurídica do Direito Internacional não podem ser dissociados do momento histórico em que viveram seus idealizadores. De fato, o estudo do Direito Internacional - assim como das ciências humanas aplicadas de modo geral - deve necessariamente levar em consideração o contexto histórico em que é realizado. O "recorte histórico" nos possibilita traçar um retrato mais fiel do desenvolvimento do Direito Internacional e de sua caracterização como ordem normativa.

Encontra-se no magistério de Rosenne (2001, p. 25) uma fiel caracterização do período histórico que influenciou as primeiras impressões do Direito Internacional. Afirma o autor a respeito do Direito Internacional da primeira metade do século XX: 
Fundado na soberania suprema do Estado, pela qual qualquer idéia de autodeterminação e interferência externa em seus assuntos internos era uma aberração, suas características centrais eram que o uso da força armada como forma de realização de políticas seria legítimo, e que o estado de guerra entre dois ou mais países, com seu impacto em outros Estados tidos como 'neutros`, era a reconhecida condição das relações internacionais e era regulada pelo Direito.

Tal constatação guarda nítida correlação com o processo histórico que teve início no século XIX. A consolidação de uma estrutura conceitual básica de Estado de Direito influência da Revolução Francesa e da promulgação da Constituição dos Estados Unidos da América - e sua natural inserção no modelo de Estado-Nação moderno produziu um Direito Internacional de co-ordenação: seu papel era fundamentalmente viabilizar as relações entre Estados independentes e autônomos, tomando a forma de um Direito meramente procedimental e que estaria a serviço dos soberanos. Marcado primariamente pela unidade era, por assim dizer, um Direito voltado para a defesa do absolutismo nacional (KOSKENNIEMI, 2004).

A transformação do cenário internacional exigiu que o Direito Internacional evoluísse para além do seu papel co-ordenador. O fracasso da Liga das Nações - por diversos motivos, dentre os quais destaca-se a relutância dos Estados Unidos da América em ingressar na organização - em evitar a eclosão de uma nova guerra em escala mundial elevou a descrença quanto às possibilidades de manutenção da ordem internacional por meio de instrumentos jurídicos. Teorias políticas - notadamente o realismo político - pareciam explicar melhor o cenário internacional, passando a fornecer aos Estados cursos de ação mais seguros e voltados à manutenção do poder.

\subsection{A EVOLUÇÃO HISTÓRICA DO DIREITO INTERNACIONAL: ORIGENS E CARACTERÍSTICAS DA FRAGMENTAÇÃO}

O fim da Segunda Guerra Mundial marca o início de uma nova etapa na evolução do Direito Internacional. A atenção do mundo volta-se pela primeira vez para a criação de uma organização internacional com amplo respaldo estatal, aparentemente equipada com meios para a realização de seu fim maior: a manutenção da paz global. Neste contexto tem gênese a Organização das Nações Unidas (ONU), instituição que apresenta uma ampla agenda política de co-operação - e não mais apenas de coordenação - entre Estados e outros sujeitos de Direito Internacional. 
O período iniciado com a criação da ONU trouxe importantes implicações quanto ao entendimento da natureza jurídica do Direito Internacional. Este não mais se configura unicamente como um Direito de co-ordenação: muito além de um mero instrumento para a defesa de interesses dos Estados, o Direito Internacional passou a incorporar projetos de transformação da comunidade internacional, projetos estes que contemplam objetivos tão complexos quanto, por exemplo, a manutenção da ordem no cenário internacional. Destarte, identifica-se no Direito Internacional duas grandes áreas, “[...] o antigo Direito de coordenação, ainda vivo no antagonismo da Guerra Fria, e o novo Direito de co-operação nos campos econômico, social e tecnológico, e em Direitos Humanos." (KOSKENNIEMI, 2004, p. 247).

O fim da Guerra Fria acrescentou importantes ingredientes para o presente debate acerca da caracterização jurídica do Direito Internacional. Finda a ameaça de mútua destruição levada a cabo pelas duas superpotências nucleares entre os anos 60 e 80, o mundo passou a experimentar um intrigante processo de crescimento econômico alavancado pela interdependência econômica entre Estados e instituições internacionais. A chamada "globalização" irradiou - e irradia - efeitos marcantes nas esferas econômica, social, cultural, política, ambiental e jurídica mundiais.

Não restam dúvidas de que o processo de globalização exerce enorme influência na dinamicidade das relações jurídicas internacionais. A concepção clássica de Direito Internacional - que até então era tradicionalmente concebido como um todo homogêneo, coerente e dotado de irrenunciável unidade - passou a ser desafiada e relativizada. A tarefa de adjudicar, interpretar e de produzir normas aptas a tutelar relações internacionais de elevadas complexidade e delineamento técnico não mais repousa, de forma exclusiva, nas mãos dos Estados nacionais.

É imperioso, nesta oportunidade, que se debata a aparente perda da unidade do Direito Internacional. Compete esclarecer, de início, que a doutrina vem se referindo ao fenômeno do desmantelamento da unidade por meio do termo fragmentação, que pode ser definido como

[...] a divisão da regulação internacional em filiais especializadas, referindo-se a interesses especiais e administradas por expertos técnicos. Ao invés de um único direito internacional, temos hoje direito dos direitos humanos, direito ambiental, direito do comércio internacional, direito penal internacional, e assim em diante [...] regimes especiais são criados com o distinto propósito de minar ou desviar-se do direito geral. (KOSKENNIEMI, 2004, p. 243) 
A análise da dialética da unidade e da fragmentação consistiria, segundo Koskenniemi (2005), em uma questão de perspectiva. A caracterização do Direito Internacional como fragmentado ou unificado seria condicionada à adoção de discursos políticos variados.

A fragmentação do Direito Internacional se desenvolve em três níveis. No primeiro nível observa-se que a hermenêutica do Direito Internacional passa a ser realizada por diferentes sujeitos, de forma a ampliar as possibilidades interpretativas e contribuindo para o desfazimento de sua unidade. Ao lado dos Estados, pode-se vislumbrar as organizações internacionais e indivíduos usufruindo de direitos e incorporando certos deveres para com a ordem jurídica transnacional. Já em um segundo nível constata-se a criação de novos regimes “às margens" das normas de Direito Internacional geral, isto é, regimes que repudiam a estrita obediência ao texto legal, preconizando a realização dos objetivos mais específicos. Nesta seara, Koskenniemi (2005) aponta para os tratados de Direitos Humanos. No terceiro nível há de se identificar a ocorrência de conflitos entre os diferentes regimes: um mesmo acontecimento pode ser visto por óticas diversas - e não raras vezes conflitantes - na medida em que os regimes fragmentados não possuem limites claros e bem definidos.

O exame da fragmentação impõe que se aprofunde o estudo da dinâmica de funcionamento de uma ordem jurídica fragmentada. $\mathrm{O}$ discurso da fragmentação introduz a existência de diferentes racionalidades, que por sua vez se dedicam a regular certos ambientes da seara global. Deste modo, podemos identificar diferenciações funcionais - a título de exemplo - nas esferas científica, tecnológica e econômica. O funcionamento das esferas fragmentadas se daria de forma autônoma. Da interação entre as diferentes racionalidades em matérias em que mais de uma racionalidade possa pretender exercer sua tutela - poderiam advir deturpações e conflitos.

Koskenniemi (2005) identifica no magistério de Luhman (1995) uma concepção mais desenvolvida de fragmentação, aqui por sua vez identificada como legal pluralism. O pluralismo legal reafirma a lógica da fragmentação, isto é, a tendência de sobreposição de uma dada racionalidade sobre todas as outras. Conseqüentemente, qualquer pretensão de hierarquização destas racionalidades logrará fracassada; eventuais conflitos entre diferentes racionalidades jamais poderão ser resolvidos. Conclui o mestre alemão, portanto, pela inexistência de uma meta-racionalidade capaz de promover uma convivência harmônica entre as mesmas. 
Desta feita, a diferenciação racional das variadas esferas normativas tem como conseqüência imediata a dissolução da unidade do Direito Internacional: "Muito distante de unificar o mundo, isso iria intensificar o embate entre regimes legais e modos de pensar, alguns mais centrais do que outros, cada qual organizado por meio de uma hierarquia interna" (KOSKENNIEMI, 2005, p. 15).

É de se observar que a lógica da fragmentação inviabilizaria um diálogo entre as diferentes racionalidades, logrando a princípio fracassadas as iniciativas de unificação do Direito Internacional. De fato, a existência de regimes dotados de racionalidades diversas traz relevantes implicações para a ordem jurídica internacional.

Galindo (2000) assevera que a presente tendência de especialização das diferentes esferas do Direito Internacional introduziria maior desordem ao último, uma vez que a manutenção da unidade seria fundamental para as ordens jurídicas. Já Koskenniemi (2005) vai além, oferecendo críticas quanto à ausência de um projeto político para a ordem internacional, uma vez que os adeptos da fragmentação ofereciam argumentos puramente descritivos, portanto insuficientes à caracterização da ordem jurídica global enquanto sistema legal apto a realizar objetivos da comunidade internacional.

\subsection{A UNIDADE DO DIREITO INTERNACIONAL}

A perda da unidade da ordem jurídica global, que conforme analisado, adviria do surgimento de esferas especializadas de auto-regulação - fenômeno identificado como fragmentação ou pluralismo legal - vem merecendo tratamento doutrinário significativo. Dos estudos destinados a propor novos alicerces para a unificação do Direito Internacional fragmentado, merece especial destaque a proposta de Günther (2001).

O referido jurista introduz a noção de um Código Universal da Legalidade capaz de conferir certa unidade a um Direito Internacional cada vez mais fragmentado. Nesta oportunidade, passa-se ao exame da citada construção teórica. O ponto de partida da proposta do citado jurista reside no reconhecimento da influência do pluralismo legal em um contexto de complexa globalização.

O legislador nacional, seja por incapacidade técnica ou morosidade, não mais se configura como instância suprema de produção normativa com aplicação em nível transnacional. A existência e o fortalecimento de sistemas auto-regulativos devem ser entendidos como inevitáveis reflexos da lógica da globalização dos mercados e do avanço 
tecnológico nos domínios do Direito Internacional. Todavia, para além de um universo plural de racionalidades normativas, o Direito - interno e internacional - estaria em constante interação com outras espécies de sistemas normativos. Desta forma, se consideradas por um ponto de vista externo, as normas legais produzidas pelas diferentes esferas e seus respectivos atores se descobririam em constante interação com outros sistemas normativos atuantes no seio social.

Neste sentido, observa Günther (2001, p.9) que - sob o enfoque antropológico - “[...] sociedades modernas não possuem apenas o Direito positivo, mas também existem vários outros atores sociais com autoridade para produzir normas válidas - tais como as normas morais ou religiosas."

O autor supramencionado entende que as análises fornecidas pelas teorias descritivas da ordem jurídica internacional fragmentada abarcam tão somente um ponto vista - externo. A restrição da perspectiva adotada reside na inaptidão para a identificação de similaridades e pontos comuns às diferentes racionalidades. Desta forma, a iniciativa para o debate entre as instâncias auto-regulativas resulta severamente prejudicada.

A partir de tal constatação, o Direito revelar-se-ia como um autêntico processo, por meio do qual as várias instâncias produtoras de normas se encontrariam em constante interação - e negociação - a fim de se determinar o conteúdo das normas legais. Assim afirma o supracitado autor:

O que é importante no Direito não é a sua estática enquanto sistema coerente de normas primárias e sua dinâmica controlada por normas secundárias, mas o contínuo processo de negociação da sua validade legal em variados níveis e em diferentes áreas sociais, diferentes formas de fazer uso do Direito, formas de evitá-lo ou assimilá-lo a outros sistemas normativos: Direito como Processo (GÜNTHER, 2001, p. 10)

Das contribuições da antropologia legal para o estudo do fenômeno da fragmentação do Direito Internacional, merece especial atenção a proposta de se engajar em uma análise do referido fato através do chamado ponto de vista interno. Günther (20010 afirma que, de um modo geral, os adeptos da perspectiva da fragmentação não raro deixam de reconhecer a dinamicidade das interações entre as diversas racionalidades, que por sua vez ocorrem em um plano interno.

Outrossim, os teóricos se esforçam para conferir completa independência e autonomia às esferas auto-regulativas, deslocando para segundo plano o debate quanto à possibilidade de harmonização das racionalidades conflitantes. Disto resulta que qualquer proposta de unificação do Direito Internacional deve estar apta a trabalhar com as diferentes 
racionalidades de maneira eficiente: deve-se construir canais de comunicação capazes de identificar elementos comuns àquelas, de modo a se chegar a uma concepção mínima de unidade ao Direito Internacional. Não há de se negar que as racionalidades fragmentadas se comunicam e interagem em um nível interno - isto é, interagem enquanto sistemas normativos legais -, e não apenas em nível externo - ou seja, com sistemas normativos tais como a moral e a religião.

Pois bem, é justamente a partir do diagnóstico da comunicabilidade entre as citadas racionalidades - ponto de vista interno - que Günther (2001) aponta para o surgimento de um Código Universal da Legalidade. O referido Código exerceria a função de uma metalinguagem destinada à comunicação entre as instâncias fragmentadas, metalinguagem esta que compreenderia elementos comuns e necessários àquelas, tais como as noções de procedimento justo, normas positivadas, reconhecimento de direitos e deveres e conceitos mínimos de sanção e competência.

De fato, a crença na possibilidade de unidade do Direito Internacional, ainda que em um contexto de marcada fragmentação, parece bastante plausível. A identificação de alicerces comuns às variadas racionalidades representa o ponto de partida à viabilidade da proposta de Günther. Deste modo, a metalinguagem introduzida pelo Código só se verifica realizável porque as diversas racionalidades partilham de elementos constitutivos irrenunciáveis, sem os quais as descaracterizariam como sistemas auto-regulados.

O maior problema reside, todavia, na delimitação do conteúdo do Código Universal da Legalidade, ou seja, a determinação de quais matérias comporiam seu núcleo essencial. Esse é, em última instância, o desafio central de qualquer proposta de unificação do Direito Internacional: como promover universalismos aptos a serem aceitos e realizados por sistemas normativos racionais distintos?

A tarefa de prover este núcleo irredutível só seria realizável por meio da adoção do procedimento democrático. Conseqüentemente, o Código Universal da Legalidade desempenharia um duplo papel em sua tarefa de catalisador da unidade do Direito Internacional:[...] o código da legalidade desempenha um duplo papel nos vários procedimentos de negociação a respeito de conceitos universais contestados: por um lado, o código da legalidade é o sujeito, o assunto controvertido destas negociações. Por outro lado, é também o meio de negociação. De acordo com a experiência histórica de autodeterminação democrática, o meio de negociação deve ser o procedimento democrático. Quanto mais possa se debater a respeito de conceitos universais

contestados do código da legalidade, mais ficamos emaranhados nos requisitos de procedimento justo que por sua vez se aproxima dos requisitos democráticos como o 
meio legítimo para a interpretação e institucionalização do código da legalidade (GÜNTHER, 2001, p. 15-16)

O papel a ser desempenhado pelo Princípio Democrático não encontra merecida elucidação no pensamento de Günther (2001). Entretanto, afirma o autor que quanto mais elementar for a compreensão acerca do papel da democracia nos domínios do Código, maiores serão as chances de se alcançar um consenso quanto ao seu conteúdo. A pretensão de universalidade do procedimento democrático a permear o Código deve ser, portanto, mínima.

É por meio da adoção do procedimento democrático que o conteúdo do Código Universal da Legalidade poderá ser identificado. O processo histórico de afirmação da democracia como processo é fundamentalmente marcado por uma estreita correlação com o desenvolvimento dos Direitos Humanos. Isso se explica pelo fato de que a democracia é concebida como condição sine qua non para a concepção de Direitos Humanos, ao mesmo tempo em que o fenômeno da positivação dos Direitos Humanos fortalece o Princípio Democrático atuante no Estado-nação e no Direito Internacional (GÜNTHER, 2001).

Portanto, a adoção do procedimento democrático como instrumento apto à identificação de um conteúdo mínimo para o Código Universal da Legalidade favoreceria uma abertura para o diálogo plural entre os setores fragmentados. A relação umbilical identificável entre o Código Universal da Legalidade e o fenômeno do surgimento/ positivação dos Direitos Humanos sinaliza para a especulação do papel a ser desempenhado pelos últimos no preenchimento do conteúdo mínimo do primeiro. Entretanto, as concepções de Direito Humanos não podem ser agrupadas sob uma única definição, fato este que realça a necessidade de discussão acerca de qual concepção estaria apta a proporcionar maior diálogo entre as instâncias fragmentadas.

\section{CONSTITUCIONALISMO GLOBAL ORGÂNICO COMO SOLUÇÃO PARA A FRAGMENTAÇÃO DO DIREITO INTERNACIONAL}

Diante da realidade fática da fragmentação por que passa o Direito Internacional, uma das soluções apresentadas é a utilização da ideia formulada por Schwöbel (2010), referente ao Constitucionalismo Global Orgânico. Antes de apresentá-lo, faz-se necessária uma aborgagem inicial sobre em que contexto o mesmo está inserido, para tanto no tópico que se segue analisar-se-á a constitucionalização do Direito Internacional e o Constitucionalismo Global. 


\subsection{CONSTITUCIONALIZAÇÃO DO DIREITO INTERNACIONAL E O CONSTITUCIONALISMO GLOBAL}

Cada vez mais se pode observar a crescente atribuição de institutos de direito constitucional ao direito internacional, e vice-versa. Isso ocorre, em grande parte, devido à confusão existente entre direitos fundamentais e direitos humanos: um mesmo direito abstratamente concebido pode ser percebido em ambas as esferas, pertencendo, então, ao gênero dos direitos fundamentais (NEUMAN, 2003), tais como liberdade de expressão, direito à vida e à integridade física e psicológica, e devido processo legal.

Diante disso, surgem dois fenômenos: a constitucionalização do direito internacional e a internacionalização do direito constitucional, que se sobrepõem no tempo e espaço. O primeiro corresponde à inserção do direito internacional nos ordenamentos jurídicos internos através das constituições dos Estados. O processo de constitucionalização do direito internacional tem origem na Declaração Relativa aos Princípios do Direito Internacional regendo as Relações Amistosas e Cooperação entre os Estados, de 1970. Alguns princípios da Declaração possuem natureza de jus cogens, como a proibição do uso ou ameaça de força, a solução pacífica de controvérsias, a não intervenção, a igualdade de direitos, a autodeterminação dos povos, a igualdade soberana dos Estados e os direitos humanos. Esses princípios, estabelecidos nas constituições dos Estados contemporâneos a fim de reger suas relações internacionais, consolidam aquisições jurídico-internacionais e elevam essas normas ao patamar de inderrogáveis, além de consagrarem valores constitucionais no direito internacional (GALINDO, 2002, p. 105-107).

Nesse sentido, a Constituição brasileira de 1988 prevê mecanismos de incorporação das normas internacionais nos artigos $5^{\circ}$, parágrafo $3^{\circ}$; 49, inciso I; e 84, inciso VIII. Além disso, as Constituições estão cada vez mais parecidas entre si, com os mesmos direitos e institutos assegurados. A constitucionalização de princípios internacionais, especialmente os relativos a direitos humanos, facilita sua fiscalização por parte dos órgãos internos de controle de constitucionalidade e, consequentemente, o controle de convencionalidade.

Por outro lado, a internacionalização do direito constitucional - e de outros ramos do direito, como o penal - corresponde a uma espécie de fertilização cruzada, em que Cortes constitucionais de diversos Estados citam-se uma às outras, e se utilizam de precedentes externos como fundamento de suas decisões (GALINDO, 2002). 
Mas o termo "internacionalização do direito constitucional" pode se referir também à atribuição de características e institutos do direito constitucional ao internacional, principalmente, com o surgimento dos tribunais internacionais de justiça, tendo como principal consequência a ideia de uma Constituição global.

Nunca é demais lembrar que o artigo $4^{\circ}$, parágrafo único, da Constituição brasileira prevê que o Brasil "buscará a integração econômica, política, social e cultural dos povos da América Latina, visando à formação de uma comunidade latino-americana de nações". No mesmo sentido, observa-se um esforço dos Estados latino-americanos para a criação de um direito comum. $\mathrm{O}$ artigo $44^{\circ}$ da Constituição peruana, por exemplo, prevê como dever do Estado a promoção da integração latino-americana.

\subsubsection{O constitucionalismo global}

O constitucionalismo global - diferentemente das teorias do Estado constitucional cooperativo (HÄBERLE, 2003), do interconstitucionalismo (CANOTILHO, 2008) e do transconstitucionalismo (NEVES, 2009) - é um movimento que ocorre no plano internacional, predominantemente. Não trata do modo como as constituições enxergam o direito internacional ou as decisões jurídicas de outros Estados, mas da forma como o direito internacional enxerga a si próprio, em razão da fragmentação de seus subsistemas, como os direitos humanos, o direito internacional penal, o direito ambiental, e outros.

A proposta do constitucionalismo global visa conferir uma organicidade, uma sistematização, a esses subsistemas, de modo a viabilizar sua efetivação pelos Estados. A evolução do constitucionalismo acompanhou a evolução do próprio direito internacional (GALINDO, 2002).

Num primeiro momento, foi importante fazer com que os Estados respeitassem tratados internacionais por meio de cláusulas que os integrassem ao direito interno. Depois, priorizou-se a aplicabilidade do direito internacional geral e a inserção dos Estados e organizações internacionais. Após a Segunda Guerra Mundial, o surgimento de organizações supranacionais se refletiu nas Constituições e, com a Guerra Fria, os Estados do chamado "terceiro mundo" tentaram modificar a estrutura do direito internacional por meio de princípios possuidores de natureza jus cogens. Intensificou-se a preocupação interna e internacional com a proteção dos direitos humanos, influenciando a elaboração de novas Constituições, dentre elas a brasileira (GALINDO, 2002).

A expressão "constitucionalismo global" é igualmente empregada por Canotilho 
(2008, p. 1370), que sugere três traços caracterizadores "deste novo paradigma emergente":

(1) alicerçamento do sistema jurídico-político em relações entre Estado/povo, isto é, não de relações horizontais entre Estados mas sim com as populações dos próprios estados; (2) emergência, através das declarações e documentos internacionais, de um jus cogens internacional (que "inclui um mínimo de proteção à vida, liberdade e segurança, no âmbito das liberdades pessoais, e o direito à autodeterminação como direito básico da democracia") legitimado em valores, princípios e regras universais; (3) a dignidade humana fixada como pressuposto de todos os constitucionalismos. Assim, compreende a transformação do Direito Internacional como um "parâmetro de validade das próprias constituições nacionais cujas normas deveriam ser consideradas nulas se violassem as normas do jus cogens internacional.

Ferrajoli (2005) percebe que tais questões decorrem de uma crise do Estado de Direito oriunda, dentre outros aspectos, da perda da unidade e coerência das fontes do direito e da convivência e superposição de diversos ordenamentos concorrentes. Vários desafios são lançados, alguns sob o aspecto liberal e outros sob o aspecto social do Estado legislativo de Direito. Justamente sob este último aspecto, é que Ferrajoli destaca como um desafio ao Estado de Direito que é a perda de soberania dos Estados que decorre justamente pelo deslocamento das fontes de Direito para além das fronteiras do Estado. Diante disto, para o autor, acarreta uma debilidade do papel garantista das Constituições nacionais.

Tendo em vista o declínio do Estado de Direito, que viu deslocado o espaço de poder para além da esfera estatal, a proposta é promover, frente a este desafio colocado pela globalização, uma integração jurídica e institucional como complemento à integração econômica e política. Para alcançar tal intento, Ferrajoli (2005) sugestiona o desenvolvimento de um constitucionalismo sem Estado, que estaria à altura dos novos espaços supraestatais.

Já para Piovesan (2007, p. 10) afirma existir uma emergência do Direito Internacional dos Direitos Humanos, principalmente no período do Pós-Guerra. Aliado a este aspecto existe uma nova feição do Direito Constitucional aberto a princípios e valores, como o da dignidade humana. A autora coloca que "é como se se projetasse a vertente de um constitucionalismo global, vocacionado a proteger direitos fundamentais e a limitar o poder do Estado."

Tendo em vista essa abertura do direito constitucional ao internacional Schwöbel (2010) propõe um constitucionalismo global orgânico, que tenta dar um passo atrás na ideia de uma Constituição global derivada de técnicas legais e valores pré-políticos, sugerindo uma 
aproximação mais fluida e flexível com o constitucionalismo, no intuito de solucionar os problemas advindos da fragmentação do Direito Internacional nesse contexto. A seguir, será a apresentada a ideia da referida autora.

\subsection{O CONSTITUCIONALISMO GLOBAL ORGÂNICO}

O constitucionalismo global é uma das áreas mais discutidas no direito internacional atualmente e, diante disso, Schwöbel (2010) deu importante contribuição com seu trabalho Organic Global Constitutionalism, ao sintetizar as tendências constitucionais predominantes no Direito Internacional Privado em quatro dimensões, quais sejam: constitucionalismo social, constitucionalismo institucional, constitucionalismo normativo e constitucionalismo analógico. A autora faz uma análise crítica desses modelos sugeridos e propõe um constitucionalismo como processo, sempre em transformação, ou seja, um constitucionalismo orgânico.

De acordo com a autora, o constitucionalismo social enfatiza que a base do constitucionalismo global reside na ideia de coexistência em uma ordem social internacional. Nesse modelo surgem preocupações políticas de participação democrática de indivíduos, a qual dará forma à sociedade internacional. A autora divide o modelo em duas subcategorias: a comunidade acadêmica internacional e a sociedade civil internacional. A primeira abriga diversos pontos de vista a respeito do Constitucionalismo Global, podendo-se destacar a ideia de um sistema baseado na Carta das Nações Unidas, como Bardo Fassbender, ou ainda tendo por orientação um sistema jurídico internacional baseado em normas peremptórias Tomuschat.

De uma maneira geral, conforme a síntese de Schwöbel (2010), essa Escola vê a "a comunidade internacional como o fórum próprio no qual a participação pode ser exercida (tanto por parte dos Estados, como de organizações não governamentais ou indivíduos)". No que se refere à vertente da "Sociedade Civil Global", destacam-se, cada qual com as particularidades próprias, as abordagens de Gunther Teubner, Andréas Fischer-Lescano e Philip Allot. Na análise de Schwöbel (2010), essa vertente tem como pressuposto a ideia do incremento da participação dos indivíduos na seara internacional. Numa alusão concernente às ordens jurídicas estatais, esse constitucionalismo de conteúdo participatório com vistas à obtenção de legitimidade é denominado de democracia constitucional.

A dimensão do Constitucionalismo Institucional, representado, entre outros, por Anne Peters e Habermas, conforme sintetiza Schwöbel (2010), dirige sua atenção para o 
poder na esfera internacional e procura a legitimá-lo por intermédio de sua institucionalização. As principais preocupações dessa dimensão situam-se em questões como a limitação e a accountability do poder através da participação e da representação, e distinguese em três tipos: o da concepção da governança global (global governance), o da Carta das Nações Unidas como Constituição Global (United Nations constitution) e o Microconstitucionalismo tornando-se Macroconstitucionalismo, o que intensifica a fragmentação do Direito Internacional. Nesse ponto, a autora cita como exemplos a OMC como uma organização internacional especializada e o direito internacional ambiental, como área temática especializada.

A esfera do Constitucionalismo Normativo procura oferecer uma estrutura para uma ordem global constitucional, cujas normas teriam um fundo moral inerente. Os autores que são inseridos nessa dimensão referem-se a essas normas como "direito mundial", "normas fundamentais" e hierarquia normativa ou "jus cogens". Conforme a síntese de Schwöbel (2010), essa dimensão abrange todos os temas chave do constitucionalismo (limitação do poder, institucionalização do poder, idealismo, estabelecimento de normas ou diretrizes e proteção de direitos dos indivíduos). Embora a escolha dos valores dependa do ponto de vista de cada abordagem, a dimensão normativa tem por premissa a existência de certas normas de caráter superior (constitucional) na ordem internacional.

Por último, a categoria do Constitucionalismo Analógico, cuja perspectiva observa as analogias entre a esfera internacional e as ordens constitucionais nacionais e regionais.

Depois de fazer essa categorização do Constitucionalismo Global conforme se apresenta nos dias atuais, a autora reconhece que todos os modelos têm seus méritos, ao tentar resolver os desafios que estão postos pelo Direito Internacional contemporâneo, entre eles a fragmentação. Entretanto, a autora reconhece a necessidade em apontar as principais fraquezas e limitações desses modelos, para ao final apresentar o Constitucionalismo Global Orgânico como solução.

A principal limitação dos modelos reside na desconsideração das complexidades e influências políticas na esfera internacional, além da utilização de preceitos democráticos liberais incompatíveis com a ordem internacional.

Outra limitação das dimensões apontadas pela autora é a busca pela universalidade no Direito Internacional, a partir da ideia que o Direito Internacional é capaz de constituir um todo organizado, fundado na unidade e homogeneidade. Um dos desafios que enfrenta essa 
ideias universalistas é justamente o fenômeno da fragmentação do Direito Internacional em diversos regimes especializados, e que formam espécies de microcosmos jurídicos dentro do Direito Internacional geral. Cada regime, em sua especialidade, tem a pretensão de ser universal, no sentido de buscar ser válido e aplicável universalmente. Como então fundamentar um constitucionalismo no direito internacional a partir desse tipo de ideia universal se, em verdade, temos são diversas ideias universalizantes, que acabam por fragmentar ainda mais o Direito Internacional?

Outra pedra de toque desses pressupostos universais para um constitucionalismo no Direito Internacional é a idealização de uma unidade na ordem jurídica internacional. Como pensar em unidade, no momento em que se presencia a proliferação de organismos e tribunais internacionais?

Corolário à ideia de unidade é a ideia de homogeneidade. Essa é outra limitação apresentada pela autora, na medida em que a busca pela unidade através da homogeneidade de modelos a serem seguidos, não passa na verdade, da sobreposição de um modelo político, econômico e cultural hegemônico, que intensifica a exclusão das minoria, e é portanto, ruim para a preservação da diversidade. Essa situação pode ser explicada com a imposição cultural, política e econômica feita pelos Estados Unidos, ou através de imposições que a União Européia faz para aceitação de novos membros, a exemplo das que faz à Turquia para fazer parte daquele bloco econômico, tentando moldar, inclusive as escolhas religiosas daquele país, já que o Islamismo constitui um temor na atualidade.

Outra contingência que atinge as propostas de constitucionalismo do Direito Internacional apontada por Schwöbel (2010) é a problemática da limitação do poder. Para a autora, muito embora a garantia de direitos individuais em uma constituição seja uma forma limitação do poder constituído, de modo que a Carta da ONU ao prevê uma série de direitos estaria limitando o poder dessa organização internacional, o possível reconhecimento da Carta da ONU como constituição do mundo, como defendem alguns constitucionalistas, aumentaria o poder da ONU como instituição, lhe garantiria a capacidade regulatória e coercitiva, tornando o tema da criação de mecanismos de limitação de poder um ponto chave, para evitar excessos e discricionariedade.

A institucionalização do poder é outro ponto frágil das propostas constitucionalistas apresentadas por Schwöbel (2010), uma vez que ela pode acarretar a dominação política de um grupo sobre outro. Nesse caso, então haveria o fortalecimento da cultura majoritária em detrimento das culturas minoritárias. 
Além disso, considerando que haja uma comunidade internacional formada por indivíduos cidadãos do mundo, como acreditam os defensores do constitucionalismo social, de que forma se dará a representatividade e a participação democrática deles no sistema internacional? Pensando adiante, num mundo repleto de diversidade cultural e religiosa, como identificar os valores comuns a todos, a ponto de serem igualados, como pretende o constitucionalismo normativo? Tal homogeneidade de valores poderia nos levar a um idealismo social, em que até os direitos humanos poderiam ser acusados de servirem de instrumento ideológico e de dominação.

Ao perceber as dificuldades a serem enfrentadas pelas diversas abordagens do Constitucionalismo Global (Social, Institucional, Normativo e Analógico), cada qual com suas particularidades e idiossincrasias que lhes são próprias e que poderiam inclusive apontar para que se abandonasse a ideia, Schwöbel (2010) elabora a proposta de uma reorientação da discussão a partir de uma concepção que denomina de "Constitucionalismo Global Orgânico" (Organic Global Constitutionalism). Segundo a referida autora, essa perspectiva difere das demais para enfrentar o debate a respeito do Constitucionalismo Global e tem por base a sugestão de quatro pontos destacados.

Inicialmente, essa reconfiguração vislumbra o Constitucionalismo Global como um processo contínuo, de maneira que rejeita a estabilidade e privilegia a flexibilidade. Nesse sentido, diferentemente das abordagens usuais, que utilizam, segundo a autora, a linguagem do constitucionalismo na perspectiva da democracia liberal e, portanto, causadora de exclusão, a perspectiva “orgânica”, por sua característica flexível, respeita a diversidade e o pluralismo.

Um segundo ponto é relacionado ao problema da politização do discurso, pois não deve ser encarado como apolítico ou neutro. Dessa forma, em vez de uma visão baseada em valores comuns "prepolíticos", o Constitucionalismo Orgânico se baseia num discurso político com ênfase na participação. Reconhecendo o pluralismo e a desunião do mundo, não se orienta no sentido de buscar um conjunto mínimo de valores comuns.

Além disso, rejeita o constitucionalismo global numa visão positive universal, que seguiria a linha da democracia liberal, e privilegia a visão negative universal. Nesse sentido, emerge do discurso das particularidades e não possui valores predeterminados e nem princípios comuns. Essa universalidade negativa deve ser entendida, segundo a autora como 
um espaço aberto, disponível, onde os diversos participantes do discurso encontrariam um espaço aberto para representar seus interesses discursivamente.

Por fim, no que concerne ao aspecto normativo, a proposta do Constitucionalismo Global Orgânico sugere que é uma promessa para o futuro, um constitucionalismo por vir. A proposta do constitucionalismo orgânico global, por ser mais crítica, densifica a mera abertura do sistema de regras e princípios, incluindo o respeito aos particularismos na universalidade do princípio da dignidade humana.

Destarte, levando em consideração que o presente trabalho tem como objetivo analisar se o constitucionalismo global orgânico poderia ser uma solução aos problemas que o Direito Internacional enfrenta em decorrência da fragmentação do mesmo, a hipótese foi positivamente afirmada na medida em que o Constitucionalismo Global Orgânico rejeita a ideia de universalidade, unidade e homogeneidade, o que acaba indo ao encontro da situação fático-jurídica que se encontra instaurada, quanto à presença cada vez maior de microcosmos jurídicos dentro do Direito Internacional geral. Conforme explanado, o Constitucionalismo Global Orgânico rejeita a estabilidade em favor da flexibilidade e essa fluidez seria capaz de agregar os mais diversos microsistemas que surgem oriundos da fragmentação do Direito Internacional, através da comunicação, participação e inclusão, que são temas chaves do Constitucionalismo Global Orgânico.

\section{CONCLUSÃO}

O feômeno da fragmentação do Direito Internacional se acentua na medida em que os processos de globalização e desenvolvimento econômico se expandem. Foi visto que a ordem do Direito Global é desafiada pelas várias instâncias de produção normativa e adjudicação.

A fragmentação do Direito Internacional em diversos regimes especializados, característica que reflete uma sociedade mundial que está cada vez mais segmentada em setores específicos, é uma das causas geradoras do conflito entre normas de Direito Internacional. Cada ramo do direito é criado com seus princípios, com normas que são pensadas para obter um resultado pré-determinado, com um modo de pensar peculiar que se afasta do Direito Internacional geral e, muitas vezes, do desconhecimento de como a matéria poderia ser tratada em outros ramos do direito, podendo gerar incompatibilidades e incongruências.

O constitucionalismo no Direito Internacional tem surgido como alternativa para resolver os problemas jurídicos que estão postos na ordem internacional. Todavia, o 
constitucionalismo de modelo democrático liberal apresenta-se como insuficiente para enfrentar os desafios neste trabalho apresentados. Não sem de mostrar hegemônico e ser instrumento de dominação de uma cultura sobre diversas outras existentes no mundo.

Por esta razão, se o constitucionalismo no Direito Internacional pode ser a saída para muitas questões, entre elas, os conflitos decorrentes da fragmentação por que passa o mesmo, esse deve ser reconfigurado, a partir das proposições de Schwöbel (2010) para um Constitucionalismo Global Orgânico. Esse constitucionalismo se diferencia da visão tradicional porque rejeita a estabilidade em favor da flexibilidade e descarta valores prépolíticos comuns em favor de uma política discursiva para o constitucionalismo. Ademais, rejeita a visão do constitucionalismo como um positivismo universal, por acreditar na preservação de particularismos. Por essa razão, essa fluidez, presente no Constitucionalismo idealizado por Schwöbel (2010) seria capaz de agregar os mais diversos microsistemas que surgem oriundos da fragmentação do Direito Internacional, através da comunicação, participação e inclusão, que são temas chaves do Constitucionalismo Global Orgânico.

\section{REFERÊNCIAS}

CANOTILHO, José Joaquim Gomes. Direito Constitucional. 7. Ed. Coimbra: Almedina, 2008. p. 1370-1371.

FERRAJOLI, Luigi. Pasado y futuro Del Estado de derecho. In: Neoconstitucionalismo(s). Trad. Miguel Carbonell. 2 ed. Madrid: Trotta, 2005, p. 20.

GALINDO, George Rodrigo Bandeira. A capacidade para celebrar tratados (treaty-making power) das organizações internacionais de integração econômica. Disponível em: http://elogica.br.inter.net/macsdp/inter.html

GÜNTHER, Klaus. Legal pluralism and the universal code of legality: globalization as a problem of legal theory. Disponível em

http://www1.law.nyu.edu/clppt/program2003/readings/gunther.pdf> Acesso: 18 junho 2015.

HÄBERLE, Peter. EI Estado constitucional. Héctor Fix-Fierro (trad). Nacional Autónoma de México. Instituto de Investigaciones Jurídicas. Serie Doctrina Jurídica, n. 47. Universidad Nacional Autónoma de México, México: 2003.

HART, Herbert L. A. O conceito de direito. A. Ribeiro Mendes (trad.). $2^{\text {a }}$ edição. Lisboa: Fundação Calouste Gulbenkian, 1994.

KELSEN, Hans. Teoria pura do direito. São Paulo: Martins Fontes, 2006. 
KOSKENNIEMI, Martti. Constitutionalism as a mindset: reflections on kantian themes about international Law and globalization. Theoretical inquiries in law. Volume 8, number 1, January 2007, article 2 .

LUHMANN, Niklas [1995]. Introdução à teoria dos sistemas: aulas publicadas por Javier Torres Nafarrate. Trad. de Ana Cristina Arantes Nasser. Petrópolis: Vozes, 2010.

NEVES, Marcelo. Transconstitucionalismo. São Paulo: Editora WMF Martins Fontes, 2009.

PIOVESAN, Flávia. Direitos Humanos e o Direito Constitucional Internacional. $8^{a}$ edição. São Paulo: Max Limonad, 2007.

SCHWÖBEL, Christine E. J. Organic global constitutionalism. Leiden Journal of International Law, 23 (2010), p. 529-553 